\title{
Observation of development of cavitation damage
}

\author{
Branislav Knížat $^{1}$, Róbert Olšiak ${ }^{1}$ and Marek Mlkvik ${ }^{1}$ \\ ${ }^{1}$ Strojnícka fakulta STU v Bratislave, Nám. slobody 17, 81231 Bratislava
}

\begin{abstract}
The paper presents a method developed and applied for observation of cavitation effects on material of different properties. It is intended for observation of cavitation effects of microorifices on selected materials. In the paper are presented some results obtained in our institute by applying of presented method.
\end{abstract}

\section{Introduction}

Cavitating flow is a phenomenon we usually want to avoid when liquids are conveyed. The reason is a considerable destructive effect of cavitating bubbles especially if they are collapsing in a vicinity of solid walls. These effects are well known and well known are also the methods how to avoid the cavitation and so increase the life cycle of hydraulic devices.

Lately new research results appear showing that the cavitation could be a promising technology in many (also non-technical) applications.

Mentioned could be for example microorganism killing in liquids, surface cleaning, non-chemical etching of surfaces, cutting of materials and disintegration of materials. The scope of application depends mainly on three base parameters which are the mechanical properties of solid material, the cavitation intensity and the time of exposure to the cavitation.

If the cavitation phenomenon should be utilized, the cavitation effects must be quantified. Time development of the surface damage causes the main problem of the quantification. Initially the damage occurs in small limited volumes where it is difficult to observe it. This is typical for materials exhibiting strain hardening - it means some metals. We developed a method of observation of a superficial damage by means of electron microscope for the purpose of capturing the extent as well as the course of the cavitation damage in an initial phase of the erosion.

In the figure 1 is a course of a cavitation damage taken from [1]. The horizontal axis corresponds to the time of an exhibition of a sample to the cavitation. The figure concerns the steel sample. It is clear that the material erosion in an initial phase is weak and it is difficult to capture it by weighing the sample.

The surface is however damaged, which may be showed by observing the sample at significant magnification in a microscope.

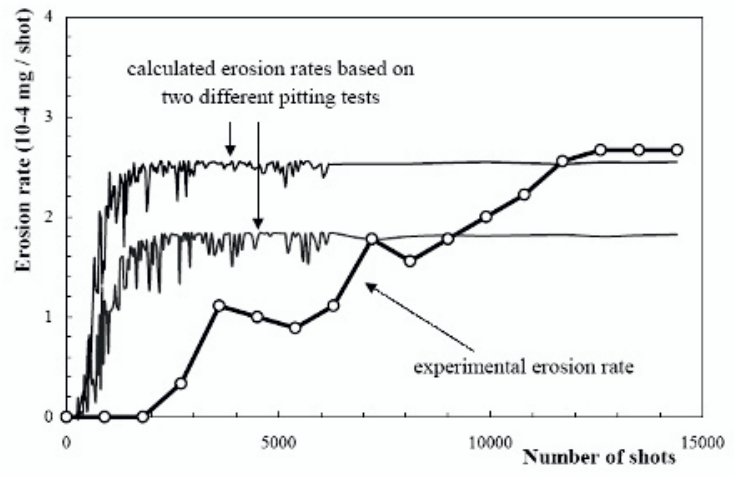

Fig. 1. Course of cavitation damage [1].

\section{Cavitating flow behind a micro-orifice.}

Cavitating flow behind the micro orifice may be described by means of cavitation number $\sigma$. It is defined for such flow as follows:

$$
\sigma=\frac{2\left(p_{2}-p_{v}\right)}{v_{2}^{2} \rho}
$$

where $\mathrm{p}_{2}-$ downstream pressure, $\mathrm{p}_{\mathrm{v}}-$ vapour pressure, $\mathrm{v}_{2}$ - velocity, $\rho$ - density.

The cavitation intensity depends on the magnitude of this number. At high values of $\sigma$ cavitating cloud collapses inside the orifice and the intensity of the cavitation is low. If the $\sigma$ is lowered the intensity of cavitation grows and the cloud collapses far behind the orifice. This phenomenon is called supercavitation. In the figure 2 is pictured the supercavitation behind the micro orifice. It is a record form high-speed camera taken from [4]. Cavitation number $\sigma$ has a value of about $\sigma=0,053$.

\footnotetext{
${ }^{\mathrm{a}}$ Corresponding author: branislav.knizat@stuba.sk
} 
The cavitating cloud behind the orifice vanishes at values about ten times greater.

Cavitation erosion depends not only on the cavitation number but also on the speed of flow and on a distance between the sample (obstacle) and orifice. The character of erosion depends on a position of a point where the cavitating flow collapses. This position depends on a time of a bubble collapse (called Rayleigh time) [2]:

$$
\tau=0.915 R_{0} \sqrt{\frac{\rho}{p_{\infty}-p_{v}}}
$$

where $\mathrm{R}_{0}$ - initial bubble radius, $\mathrm{p}_{\infty}$ - pressure of the surroundings, $\mathrm{p}_{\mathrm{v}}-$ vapour pressure.

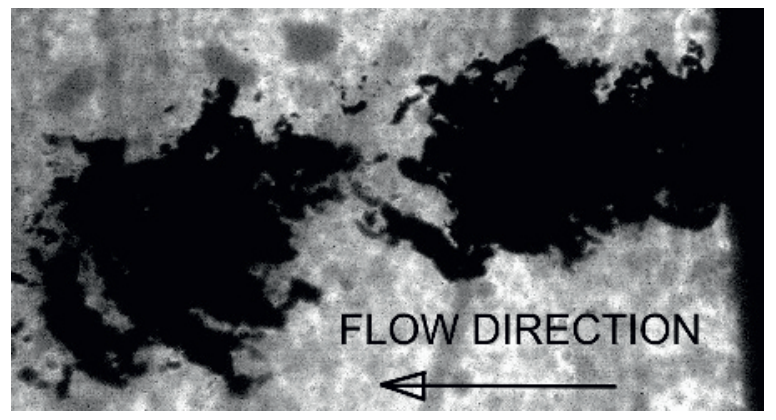

Fig. 2. Typical flow patterns of cavitation cloud at $\sigma=0,053$ (supercavitation).

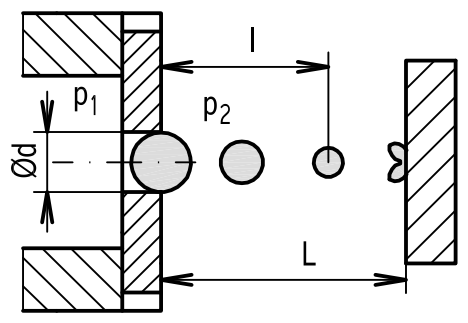

Fig. 3. The collapse of a cloud on a sample.

Rayleigh time characterizes the lifetime of a bubble and by such manner at given speed also the point where it collapses - figure 3 .

\section{Observation of cavitation damage}

For the evaluation of cavitation effects on different materials are utilized methods enabling quantitative and qualitative evaluation of the total damage. As it follows from [2] it is necessary to judge not only the absolute loss of eroded mass, but also the character of a damage of the surface. It is dependent on different parameters of flow settings. The effect of cavitating flow is concentrated or dispersed on a wide area on the surface of selected sample. Also the time course of the erosion is important. Usually it is convenient to apply more methods of observation at the same time. A mass loss observation of eroded material is described in [4].

This method is very appropriate for utilization in a case of materials exhibiting considerable loss of material volume (for example disintegration of rocks).

\section{Experimental device}

Detailed description of the experimental device can be found in [3], [4], [5]. A base part is the Lichtarowicz cell with a micro orifice. The device enables an observation of both shape and structure of a cavitating cloud by means of high - speed camera. Some results were presented in [3]. The micro orifice itself is depicted in the figure 4 . The results described and presented in this paper were received with the orifice of a diameter $\mathrm{d}=0,300 \mathrm{~mm}$. Next parameters were: upstream pressure $\mathrm{p}_{1}=13,5 \mathrm{MPa}$; downstream pressure $\mathrm{p}_{2}=0,12 \mathrm{MPa}$; mass flow rate $\mathrm{Q}_{\mathrm{m}}=0,014 \mathrm{~kg} / \mathrm{s}$.

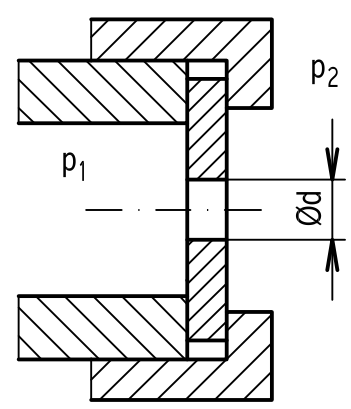

Fig. 4. Micro-orifice.

Table 1. Material of samples.

\begin{tabular}{|c|c|c|c|}
\hline & A & B & C \\
\hline Material & Dural & Brass & Steel A321 \\
\hline
\end{tabular}

For an observation of cavitation damage we took 3 different metal materials according the Table 1.

\section{Results of experiment}

An evaluation if an initial phase of the damage by using the electron microscope was the aim of the experiment. An area of a damaged surface was evaluated, because initially the mass of an eroded material is difficult to estimate. Generally it may be stated, that during our experiments we found two types of a surface damage. These are depicted in the figure 5. In the upper part of the figure is a type of a damage typical for samples A (dural) and B (brass). The damage starts with small pits, which are gradually increasing and overlapping. Later the damaged region is not increasing horizontally, but the process continues vertically (deeper under the surface). The second type is typical for materials exhibiting a strain hardening, especially for steels. For this damage is typical that the pits do not occur in more points. The damage starts in the middle of the jet and grows further. Later again the horizontal growing of the damaged surface stops and growing continues in vertical direction as in previous case. It may be seen from the lower part of the figure 5 . 
We estimated a non-dimensional area of the damage as a ratio of damaged area to the area of the opening of the orifice:

$$
\alpha=A / A_{0}
$$

where A - damaged area; Ao - area of the opening of the micro-orifice.

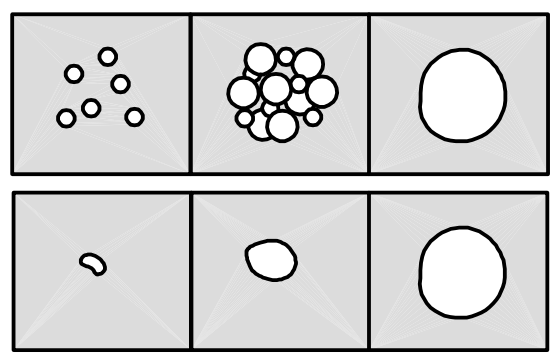

Fig. 5. Scheme of superficial damage due to cavitation.

In the figures from 6 to 11 are the images made by an electron microscope at different magnification.
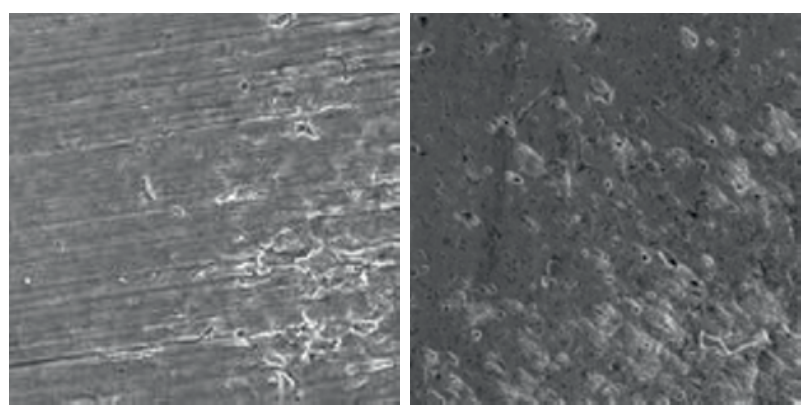

Fig. 6. Pits: Dural (sample A) and Brass (sample B).
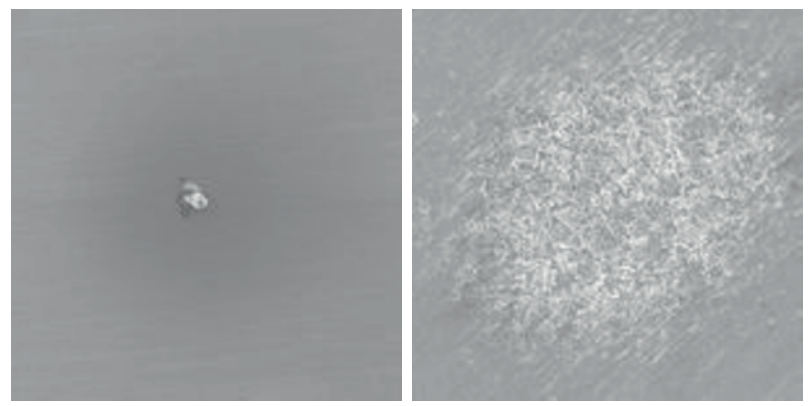

Fig. 7. Steel (sample C): $60 \mathrm{~min}$ (left) and $300 \mathrm{~min}$ (right).

In the figure 6 are starting pits, which are growing and overlapping - samples A and B. Typical course of the damage of steel (sample C) is in the figure 7. Left is the origin of the damage after $60 \mathrm{~min}$. and right is the damage after $300 \mathrm{~min}$. of exposure to the cavitation. Difference between the figure 6 and figure 7 is caused by the self-hardening ability of steel. In the figure 8 and the figure 9 are depicted different phases of a cavitation damage of the sample $\mathrm{C}$.

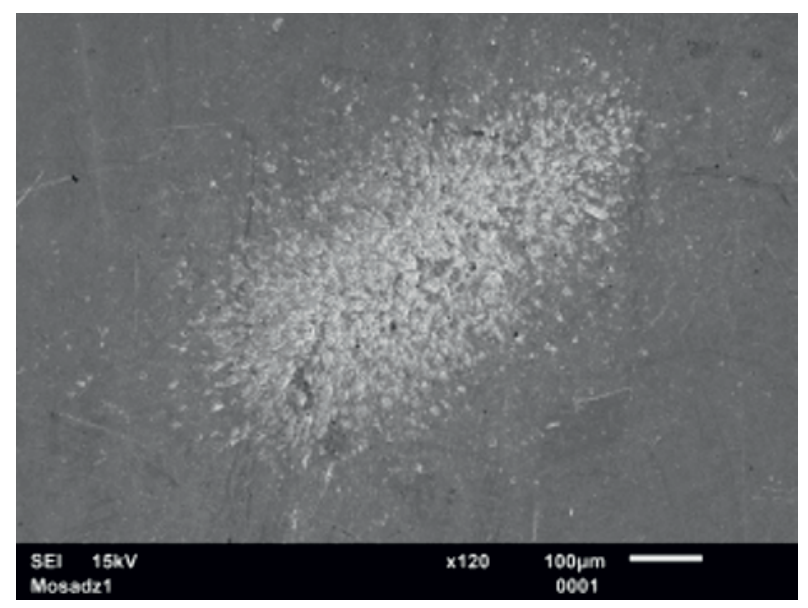

Fig. 8. Course of superficial damage - sample B (30 min).

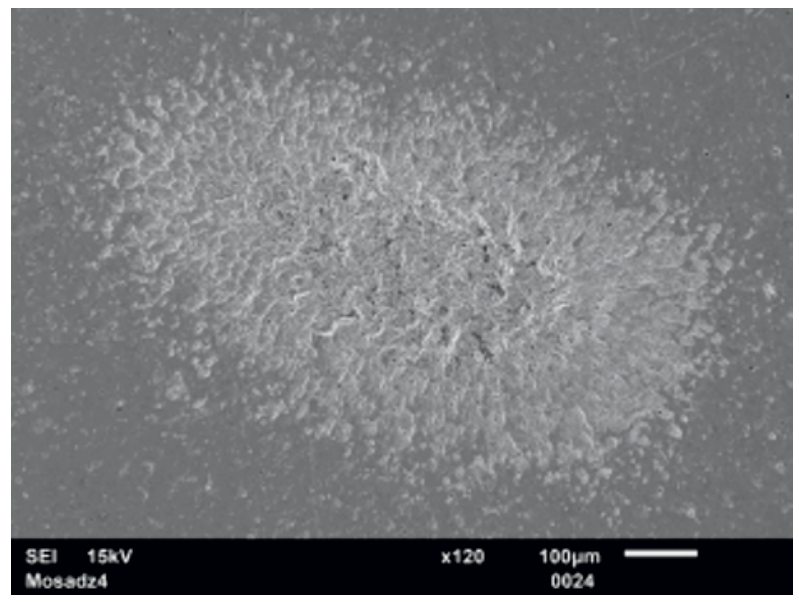

Fig. 9. Course of superficial damage - sample B (300 $\min )$.
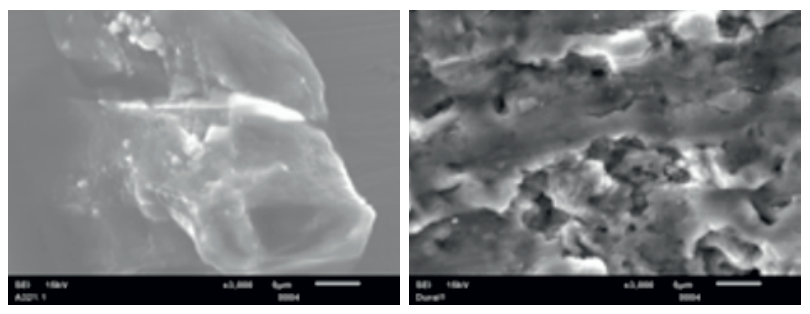

Fig. 10. Maginification 3000x C (60 min) and A (30 min)
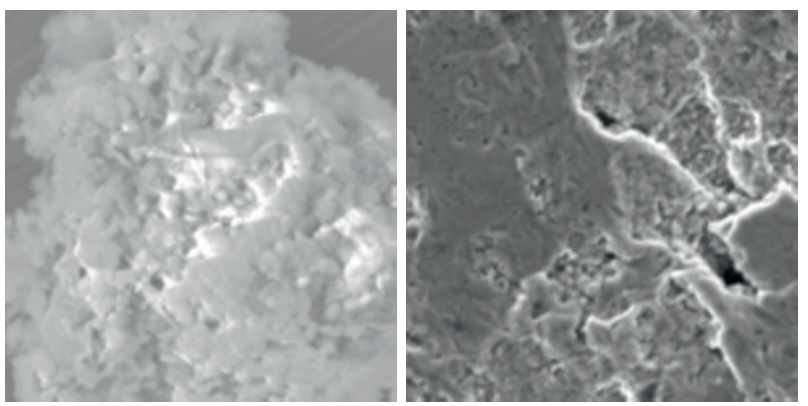

Fig. 11. Maginification 3000x C (240 min) and B (120 min)

In the figure 8 is not finished the initial phase of erosion of the original surface. In the figure 9 starts the second part of a damage - deep damage of subsurface sheets of 
the sample. In the figure 10 and figure 11 is depicted a character of the damage (shape of pits) in a magnification of $3000 x$.

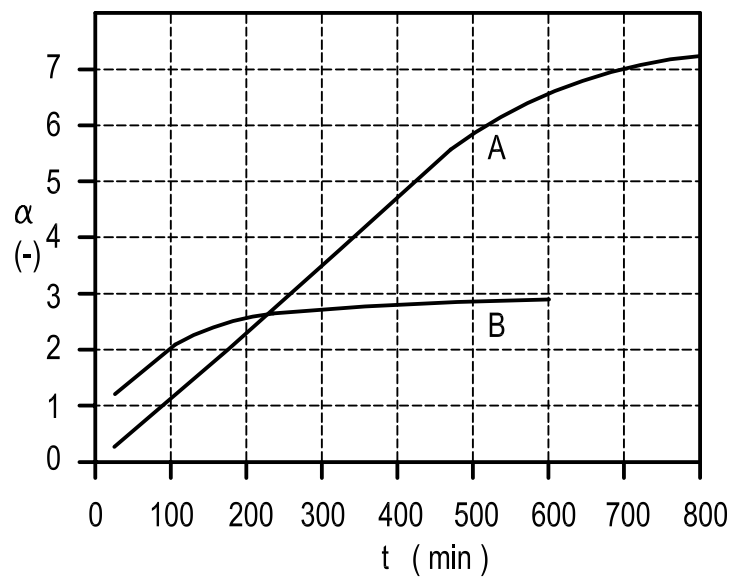

Fig. 12. Time course of a cavitation damage of samples A, B.

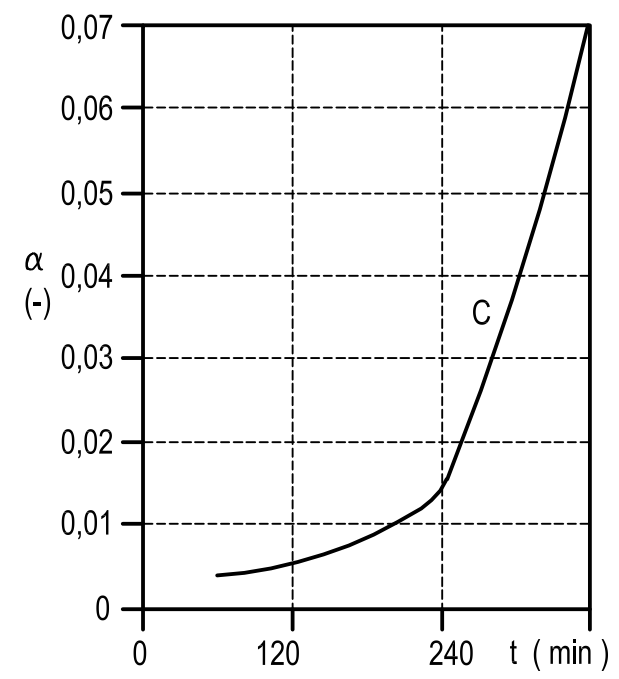

Fig. 13. Time course of a cavitation damage of the sample $\mathrm{C}$.

In the figure 12 and figure 13 is a time course of the superficial cavitation damage obtained by an evaluation of images from electron microscope. Horizontal axis represents $\alpha$ given by the formula (3). It is clear that the superficial damage of samples A (dural) and B (brass) reaches relatively fast its limit. The damaged area is 3 time (sample B) or 7 times (sample A) greater then the area of the orifice opening. On the other hand the steel sample is more resistive and the loss of material is lower. The erosion starts shortly after the time $240 \mathrm{~min}$. This phenomenon is probably caused by a cyclic load of the of the sample surface.

\section{Conclusion}

The method of the evaluation of the superficial cavitation damage of metal surfaces by means of images from an electron microscope was presented in the paper. Three types of metal material were compared: steel, dural and brass. This method is especially intended for an evaluation of the initial phase of the damage when other methods (weighing of eroded mass of a sample) have a very low accuracy. This method for a damage analysis is appropriate for very resistive materials and low power of a cavitating stream. It is a visualization method but the results are quantitatively comparable. Thanks to the considerable magnification available in the microscope it is possible to observe the cavitation erosion during the first minutes of the sample exposure to the flow. Depending on the material sort, two types of the cavitation damage may be observed. Materials as for example brass or dural exhibit a continuous rate of damage during the experiment. Materials as for example steel exhibit due to strain hardening a low damage rate in the first phase of experiment. The damage rate of these materials increases later - when the hardened layer starts to erode.

\section{Acknowledgments}

This work was supported by the Scientific Grant Agency VEGA under contract number 1/0215/11.

\section{References}

1. N. Berchiche, J.P. Franc, J.M. Michel: A Cavitation Erosion Model for Ductile Materials, CAV2001:sessionA3.001, 2001

2. C. Haosheng, L. Yongjian, C. Darong, W. Jiadao: Experimental and numerical investigations on development of cavitation erosion pits on solid surface, Tribology Letters, Vol. 26, No. 2, May 2007

3. M. Mlkvik, R. Olšiak, B. Knížat: Visualization of the Cavitating Jet Using Flashlamp For Illumination. Experimental Fluid Mechanics 2011, Proc. of the Intern. Conference, Jičín, 2011.

4. M. Mlkvik Výskum viacfázových tokov v hydraulických kanáloch vel'mi malých rozmerov, $\mathrm{SjF}$ STU v Bratislave, 2012

5. R. Olšiak, M. Mlkvik, B. Knížat: Visualization of Submerged Cavitating Jet Benhind The Micro Orifice, 15th International Symposium on Flow Visualization, June 25-28, 2012, Minsk, Belarus 